Revista Destaques Acadêmicos, Lajeado, v. 11, n. 3, 2019. ISSN 2176-3070

DOI: http://dx.doi.org/10.22410/issn.2176-3070.v11i3a2019.2273

http://www.univates.br/revistas

\title{
A PERCEPÇÃO DOS PROFISSIONAIS DA ÁREA OBSTÉTRICA DE DOIS HOSPITAIS DO VALE DO TAQUARI SOBRE O PARTO HUMANIZADO
}

\author{
Édina Cléia Ahlert ${ }^{1}$, Alessandro Menna Alves², Paula Michele Lohmann ${ }^{3}$
}

Resumo: Ao longo dos anos, o entendimento sobre o parto e o nascimento foram sendo modificados, deixando de ser entendido como um processo fisiológico, e sim como uma patologia, no qual a mulher deixa de ser protagonista, e o profissional de saúde assume esta posição. Na tentativa de reverter isso, o Ministério da Saúde/Brasil lançou o Programa de Humanização ao Pré-Natal e Nascimento e a portaria sobre a Rede Cegonha, os quais indicam aos profissionais os princípios de um parto humanizado. Entretanto, a literatura ainda mostra que os profissionais ainda não conseguem aplicála de maneira ideal. Baseado nisso, o objetivo deste estudo foi avaliar a percepção dos profissionais da área obstétrica de dois hospitais do Vale do Taquari sobre o parto humanizado. Para isto, foi utilizado um questionário, o qual tinha questões quantitativas e qualitativas. Os principais resultados mostram que os profissionais entrevistados possuem bom conhecimento sobre o parto humanizado e seus princípios, além dos hospitais incentivarem a sua prática. Sendo assim, este estudo mostra que as equipes dos dois hospitais estão bem capacitadas para a realização de um parto humanizado. Entretanto, como não foram entrevistadas gestantes, não é possível afirmar se estes conceitos são colocados efetivamente em prática.

Palavras-chave: Parto Humanizado. Humanização da Assistência. Obstetrícia. Política de Saúde.

\section{INTRODUÇÃO}

O parto sofreu grandes modificações ao longo dos anos em relação ao seu modelo assistencial. Por muitos anos o ato de parir era considerado

1 Graduanda do Curso de Enfermagem da Universidade do Vale do Taquari - Univates, eahlert@universo.univates.br

2 Dr. Professor do Curso de Odontologia da Universidade do Vale do Taquari - Univates, alessandro.alves@univates.br

3 Ms. Enfermeira e professora do Curso de Enfermagem da Universidade do Vale do Taquari Univates, paulalohmann@univates.br 
"assunto de mulher", no qual as parteiras ajudavam na parturição e na criação de um clima emocional favorável para a parturiente, compartilhando intimamente suas experiências e habilidades vindas de suas próprias histórias de vida (MATEI et al., 2003). Devido às altas taxas de mortalidade materna e infantil, a visão do parto como algo fisiológico foi alterada pela medicina em meados do século XX, mais especificamente depois da Segunda Guerra Mundial, que transformou o parto em um evento patológico, que necessitava de intervenções cirúrgicas e medicamentosas, no qual o hospital seria o local ideal de sua realização (PINHEIRO; BITTAR, 2012). Além disso, começou a surgir na assistência ao parto a figura do cirurgião e a crescente inclusão da posição de decúbito dorsal para facilitar o trabalho médico e a utilização de seus instrumentos. A institucionalização do atendimento médico e do parto reduziu as taxas de morbimortalidade perinatal e materna, porém de outro lado acabou tornando-o menos humanizado, e, consequentemente, a mulher deixou de ser sujeito da ação para tornar-se objeto (SCHMALFUSS et al., 2010).

Tentando mudar o significado do medo e da dor relacionado ao parto normal, as enfermeiras obstetras passaram a aplicar a política de parto humanizado, com o intuito de diminuir os elevados números de nascimentos por cesarianas que acabavam sendo realizadas de forma desnecessária (PINHEIRO; BITTAR, 2012). A humanização baseia-se em aspectos fundamentais, dentre eles de que é dever das unidades de saúde receber a parturiente, seus familiares e recém-nascidos com dignidade, requerendo assim, atitude ética e solidária por parte da equipe multiprofissional, fazendo desta unidade de saúde um ambiente acolhedor, que transmita segurança e confiança a mulher. Outro aspecto bastante relevante que a humanização tem por prioridade, é referente à adoção de medidas e procedimentos que são benéficos para o acompanhamento do parto e nascimento, evitando práticas desnecessárias, que embora muito realizadas, não beneficiam a mulher nem o recém-nascido, e que acabam por gerar maiores riscos para ambos (BRASIL, 2002). O Ministério da Saúde (BRASIL, 2001) reforça que, a mulher pode deambular, sentar e deitar durante o trabalho de parto, como também ser encorajada e apoiada na escolha da posição a qual deseja parir, exceto em algumas exceções, que possam vir a ser prejudiciais, colocando em risco a vida e a saúde tanto do bebê quanto a da mãe, necessitando assim de que a parturiente permaneça deitada no leito.

Com a criação do Programa de Humanização ao Pré-natal e Nascimento (PHPN), estabelecida pela portaria $\mathrm{n}^{\circ} 569$, de 01/06/2000, do Ministério da Saúde, pode-se dizer que um grande passo na luta pela humanização do parto foi dado no Brasil (GRIBOSKI; GUILHEM, 2006). Tem por objetivo principal resgatar a dignidade da mulher durante o processo parturitivo, priorizando o parto vaginal e a redução de intervenções cirúrgicas desnecessárias, ou seja, a cesárea, acabando assim por gerar uma transformação da assistência, durante a gestação, parto e puerpério, tornando principalmente o parto um processo mais ativo por parte da mulher (GRIBOSKI; GUILHEM, 2006). Existe também 
uma portaria mais recente, de extrema relevância na história da humanização do parto e direito da mulher e da criança, a Portaria ${ }^{\circ} 1.459$ de 24 de junho de 2011, que institui no âmbito do Sistema Único de Saúde (SUS) a Rede Cegonha, onde a mesma visa assegurar à mulher o direito ao planejamento reprodutivo e a atenção humanizada à gravidez, ao parto e ao puerpério.

As ações desenvolvidas pelo PHPN têm influência no modelo organizacional dos serviços de saúde e seus Centros Obstétricos (COs), onde prioriza uma assistência voltada à necessidade das mulheres e suas famílias. Realiza assim, modificações nas estruturas dos COs, transformando-os em um espaço acolhedor, favorecendo a prática da humanização da assistência a parturiente. Portanto, além da estrutura física, são imprescindíveis as ações dos profissionais de saúde e o atendimento prestado, requerendo que os mesmos tenham como regra, de que a forma como o parto é assistido e vivenciado, pode vir a ser fator decisivo para uma maternidade segura, tratando assim, este momento, como único e especial, tanto para a mãe, quanto para o bebê (BUSANELLO et al., 2011).

Os principais obstáculos enfrentados para a prática da humanização no parto e nascimento é a resistência de alguns profissionais de saúde, que não conseguem e também não querem enquadrar-se dentro das práticas humanizadas. Outro obstáculo enfrentado é baseado na sua formação profissional, que é pautada no modelo biomédico, ou seja, um atendimento que utiliza métodos tecnológicos, não priorizando as práticas humanizadas, causando um consequente despreparo e desqualificação da equipe nos atendimentos. Uma das soluções é o investimento na atualização dos conhecimentos, aperfeiçoando e treinando os profissionais de saúde, para que suas técnicas sejam voltadas a um padrão de atendimento humanizado ao parto e ao recém-nascido. Porém alguns profissionais reconhecem a necessidade de mudança, e busca novos conhecimentos das atualizações de médicos e enfermeiros (MALHEIROS et al., 2012).

Sendo assim, o objetivo deste trabalho foi avaliar a percepção dos profissionais da área obstétrica de dois hospitais do Vale do Taquari em relação ao parto humanizado.

\section{MÉTODO}

Trata-se de uma pesquisa de caráter exploratório-descritivo com abordagem qualitativa e quantitativa. A amostra foi por censo, uma vez que o número de profissionais a serem entrevistados é pequeno. Ao total, foram convidados a participar 23 profissionais da área obstétrica em dois hospitais do Vale do Taquari pertencentes à Rede Cegonha. Este trabalho foi aprovado pelo Comitê de Ética em Pesquisa sob o número CAAE 97832318.0.0000.5310.

De acordo com os dados disponibilizados por estes hospitais, foram entrevistados 23 profissionais. No hospital 1, foram entrevistados 11 
profissionais: cinco médicos, dois enfermeiros e quatro técnicos de enfermagem. Já no hospital 2, foram entrevistados 9 profissionais: quatro médicos, dois enfermeiros e três técnicos de enfermagem. Este número de indivíduos foi disponibilizado pelos dois hospitais, durante visita para o preenchimento do termo de anuência para a realização da pesquisa.

O critério de inclusão foi ser médico, enfermeiro ou técnico de enfermagem que atuam no setor da obstetrícia. Já o critério de exclusão foi possuir menos de seis meses de atuação na área obstétrica do hospital no qual exerce sua função atualmente.

A coleta de dados realizou-se através de questionário estruturado, formulado pelo pesquisador e aplicado conforme critérios de inclusão e exclusão citados anteriormente. A coleta realizou-se no mês de outubro de 2018 em dois hospitais do Vale do Taquari/RS, após aprovação do Comitê de Ética em Pesquisa da Univates. Os dois hospitais assinaram o termo de anuência para a realização da pesquisa. Para iniciar a coleta de dados, o pesquisador deixou de forma clara, quais são os objetivos da aplicação do questionário da pesquisa. Foi levada em consideração a disponibilidade do entrevistado e do pesquisador, sendo combinados previamente por telefone. O consentimento para a realização da aplicação do questionário aos participantes do referido estudo, foi através do termo de consentimento livre e esclarecido, sendo assinada em duas vias, ficando uma com o entrevistado, e outra com o entrevistador.

O instrumento da pesquisa foi construído pelo pesquisador, e contém 09 (nove) questões para caracterização dos sujeitos da pesquisa, 02 (duas) questões avaliando o conhecimento do profissional sobre o parto humanizado, 07 (sete) questões envolvendo as práticas seguidas pelo hospital e 04 (quatro) questões que se referem ao olhar do profissional em relação ao parto humanizado e seu ambiente de trabalho.

Para as variáveis qualitativas, foi realizada a análise de conteúdo de acordo com os critérios de Laurence Bardin (2011). Já em relação às variáveis quantitativas, elaborou-se uma planilha no Excel e foram analisados descritivamente e apresentados através de número, porcentagem, média e desvio padrão ou mediana e intervalo de confiança.

\section{RESULTADOS}

Dos 20 profissionais entrevistados (TABELA 1), 50,0\% (10) eram técnicos em enfermagem, 20,0\% (4) enfermeiros e 30,0\% (6) médicos, maioria do sexo feminino $(85,0 \%)$ e na faixa etária dos 30-39 anos (70,0\%). Destes, 80,0\% (16) atuavam no hospital 2 e 20,0\% (4) profissionais no hospital 1 . A maioria dos profissionais $60,0 \%$ tem de 5-10 anos de formados, tendo por local de formação $60,0 \%$ de (12) destes profissionais diferentes escolas técnicas e universidades do Rio Grande do Sul, e 40,0\% (8) profissionais como formação a Universidade 
do Vale do Taquari - Univates. Sendo que destes profissionais entrevistados a grande maioria $45,0 \%$, possui até 5 anos de atuação na área obstétrica.

Tabela 1: Característica dos profissionais

\begin{tabular}{|c|c|c|}
\hline Característica & Frequência absoluta (n) & Frequência relativa (\%) \\
\hline $\begin{array}{l}\text { Idade (anos) } \\
20-29 \\
30-39 \\
40-49 \\
50-59\end{array}$ & $\begin{array}{c}3 \\
14 \\
2 \\
1\end{array}$ & $\begin{array}{c}15,0 \\
70,0 \\
10,0 \\
5,0\end{array}$ \\
\hline $\begin{array}{l}\text { Sexo } \\
\text { Feminino } \\
\text { Masculino }\end{array}$ & $\begin{array}{c}17 \\
3 \\
\end{array}$ & $\begin{array}{l}85,0 \\
15,0\end{array}$ \\
\hline $\begin{array}{l}\text { Hospital } \\
1 \\
2 \\
\end{array}$ & $\begin{array}{c}4 \\
16 \\
\end{array}$ & $\begin{array}{l}20,0 \\
80,0 \\
\end{array}$ \\
\hline $\begin{array}{l}\text { Profissão } \\
\text { Técnico em Enfermagem } \\
\text { Enfermeiro } \\
\text { Médico }\end{array}$ & $\begin{array}{l}10 \\
4 \\
6\end{array}$ & $\begin{array}{l}50,0 \\
20,0 \\
30,0\end{array}$ \\
\hline $\begin{array}{l}\text { Tempo de formado (anos) } \\
0-5 \\
6-10 \\
\text { mais de } 10\end{array}$ & $\begin{array}{l}6 \\
6 \\
8\end{array}$ & $\begin{array}{l}30,0 \\
30,0 \\
40,0\end{array}$ \\
\hline $\begin{array}{l}\text { Local de formação } \\
\text { Univates } \\
\text { Outras }\end{array}$ & $\begin{array}{c}8 \\
12\end{array}$ & $\begin{array}{l}40,0 \\
60,0\end{array}$ \\
\hline $\begin{array}{l}\text { Tempo de atuação na área } \\
\text { obstétrica (anos) } \\
0-5 \\
6-10 \\
\text { mais de } 10\end{array}$ & $\begin{array}{l}9 \\
6 \\
5\end{array}$ & $\begin{array}{l}45,0 \\
30,0 \\
25,0\end{array}$ \\
\hline
\end{tabular}

Em relação ao conhecimento sobre o parto humanizado (TABELA 2), todos os profissionais entrevistados responderam ter conhecimento sobre o que é o parto humanizado, sendo citada como item de maior importância, por $80,0 \%$ (16) profissionais, a autonomia da mulher nas decisões.

Tabela 2: conhecimento do profissional sobre o parto humanizado

\begin{tabular}{l|c|c}
\hline \multicolumn{1}{c|}{ Pergunta } & $\begin{array}{c}\text { Frequência } \\
\text { absoluta (n) }\end{array}$ & $\begin{array}{c}\text { Frequência } \\
\text { relativa (\%) }\end{array}$ \\
\hline Você sabe o que é parto humanizado? & 20 & 100,0 \\
Sim & 0 & 0,0 \\
Não & & \\
\hline
\end{tabular}




\begin{tabular}{l|c|c}
\hline \multicolumn{1}{c|}{ Pergunta } & $\begin{array}{c}\text { Frequência } \\
\text { absoluta (n) }\end{array}$ & $\begin{array}{c}\text { Frequência } \\
\text { relativa (\%) }\end{array}$ \\
\hline $\begin{array}{l}\text { Dos itens citados abaixo, qual você entende como } \\
\text { sendo o de maior importância na prática do parto } \\
\text { humanizado? }\end{array}$ & & \\
Utilização da bola para dilatação do períneo & 1 & 5,0 \\
Técnicas de relaxamento (água/banheira) & 3 & 15,0 \\
Presença de acompanhante no processo de parto & 8 & 40,0 \\
Sem intervenção medicamentosa & 0 & 0,0 \\
Autonomia da mulher nas decisões & 16 & 80,0 \\
Segurança ao binômio mãe-bebê & 1 & 5,0 \\
\hline
\end{tabular}

Já sobre as práticas seguidas pelo hospital (TABELA 3), dos (20) profissionais entrevistados, $80,0 \%$ (16) destes relatam cesárea como tipo de parto mais vivenciado, sendo que $50,0 \%$ (10) profissionais apontam como escolha médica para a realização de cesárea. Já em relação ao parto normal, $65,0 \%$ (13) profissionais apontam que, quando realizados é por opção da mulher, e em contrapartida $25,0 \%$ (5) profissionais atribuem como escolha médica. Dos (20) profissionais entrevistados, todos relatam repassar informações às gestantes durante todo o período de pré-parto, parto e pós-parto. Sendo que $95,0 \%$ (19) profissionais relatam que a escolha pela via de parto é realizada junto com a gestante. Em relação a permitir a participação do acompanhante na hora do parto, os 100\% (20) profissionais, responderam que sim, permitem a participação, como também todos os profissionais entrevistados responderam que praticam o acolhimento a família.

Tabela 3: Práticas seguidas pelo hospital

\begin{tabular}{l|c|c}
\hline \multicolumn{1}{c|}{ Pergunta } & $\begin{array}{c}\text { Frequência } \\
\text { absoluta (n) }\end{array}$ & $\begin{array}{c}\text { Frequência } \\
\text { relativa (\%) }\end{array}$ \\
\hline Qual o tipo de parto mais vivenciado por você? & 16 & 80,0 \\
Cesárea & 5 & 25,0 \\
Normal Vaginal & & \\
\hline Critério de escolha para o parto cesáreo & 10 & 50,0 \\
Escolha médica & 7 & 35,0 \\
Medo da dor do parto & 0 & 0,0 \\
Preservar a anatomia da genitália externa & 7 & 35,0 \\
Complicações médicas & 5 & 25,0 \\
Indicações médicas & & \\
\hline Critério de escolha para o parto normal & 5 & 25,0 \\
Escolha médica & 7 & 35,0 \\
Recuperação mais rápida & 9 & 45,0 \\
Benefícios à saúde do bebê & 13 & 65,0 \\
Opção da mulher & & \\
\hline
\end{tabular}




\begin{tabular}{l|c|c}
\hline \multicolumn{1}{c|}{ Pergunta } & $\begin{array}{c}\text { Frequência } \\
\text { absoluta (n) }\end{array}$ & $\begin{array}{c}\text { Frequência } \\
\text { relativa (\%) }\end{array}$ \\
\hline $\begin{array}{l}\text { São repassados informações às gestantes durante o } \\
\text { período de pré-parto, parto e pós -parto? }\end{array}$ & 20 & \\
Sim & 0 & 100,0 \\
Não & & 0,0 \\
\hline A decisão de escolha pela via de parto é realizada & 19 & \\
junto com a gestante? & 1 & 95,0 \\
Sim & & 5,0 \\
Não & 20 & 100,0 \\
\hline Permitem a participação do acompanhante na hora & 0 & 0,0 \\
do parto? & & \\
Sim & 20 & 100,0 \\
Não & 0 & 0,0 \\
\hline Praticam o acolhimento à família? & & \\
Sim & & \\
Não & & \\
\hline
\end{tabular}

E, por último, sobre o olhar do profissional ao parto humanizado e o seu ambiente de trabalho (TABELA 4), dos 20 profissionais entrevistados, $55,0 \%$ (11), consideram a comunicação entre a equipe obstétrica em relação ao atendimento á mulher e ao bebê durante o pré-parto, parto e pós-parto como muito boa, sendo que apenas 10\% (2) dos (20) profissionais entrevistados apontam como sendo regular. Em questão a realização da educação continuada com os profissionais da área obstétrica à respeito do tema parto humanizado, $70,0 \%$ (14) profissionais responderam que sim, o hospital realiza educação continuada, sendo também relatado por $95,0 \%$ (19) profissionais que o hospital na qual exercem sua função preconiza o parto humanizado.

Tabela 4: o olhar do profissional em relação ao parto humanizado e o seu ambiente de trabalho

\begin{tabular}{l|c|c}
\hline \multicolumn{1}{c|}{ Pergunta } & $\begin{array}{c}\text { Frequência } \\
\text { absoluta (n) }\end{array}$ & $\begin{array}{c}\text { Frequência } \\
\text { relativa (\%) }\end{array}$ \\
\hline $\begin{array}{l}\text { Como você considera a comunicação entre a equipe } \\
\text { obstétrica em relação ao atendimento à mulher e ao } \\
\text { bebê durante o pré-parto, parto e pós-parto? }\end{array}$ & & \\
Muito boa & 11 & 55,0 \\
Boa & 7 & 35,0 \\
Regular & 2 & 10,0 \\
Ruim & 0 & 0,0 \\
\hline O hospital realiza educação continuada com os & & \\
profissionais da área obstétrica à respeito do tema & & \\
parto humanizado?* & 14 & 70,0 \\
Sim & 5 & 25,0 \\
Não & & \\
\hline
\end{tabular}




\begin{tabular}{l|c|c}
\hline \multicolumn{1}{c|}{ Pergunta } & $\begin{array}{c}\text { Frequência } \\
\text { absoluta (n) }\end{array}$ & $\begin{array}{c}\text { Frequência } \\
\text { relativa (\%) }\end{array}$ \\
\hline O hospital preconiza o parto humanizado? & 19 & \\
Sim & 1 & 95,0 \\
Não & 5,0 \\
\hline
\end{tabular}

\section{DISCUSSÃO}

Em relação à pesquisa, todos os participantes relataram ter conhecimento sobre o que é o parto humanizado, apontando como principal importância e relevância da prática a humanização do parto a autonomia da mulher nas decisões, menor número de intervenções possíveis, participação ativa da gestante, escuta ativa, acolhimento, respeito aos desejos e vontades da gestante, presença de acompanhante, sentimento de confiança para com a equipe na qual é assistida, oferecendo um ambiente tranquilo, aconchegante, deixando-a livre para deambular. Sendo, portanto condizente com o que a literatura nos traz em relação às práticas humanizadas, porém as condutas que compõem a humanização do parto devem ser postas em prática durante todo o período de pré-parto, parto e pós-parto, pois é a trajetória percorrida por todo o período gestacional, que desencadeia ou não a um parto natural (vaginal) (MENEZES E DIAS, 2012). O parto cesáreo é indicado em ocasiões onde o parto vaginal possa acarretar risco de vida à mãe e/ou ao bebê, sendo assim, ainda é possível exercer práticas as mais humanizadas possíveis, como por exemplo, presença de acompanhante, ambiente acolhedor, manter a gestante e familiar a par de todos os processos, contato imediato do bebê com a mãe logo após o nascimento, aleitamento materno na primeira hora de vida, acolhimento da puérpera na sala de recuperação, apresentar o recém-nascido a demais familiares, dentre outros fatores (NOGUEIRA, 2017). Questões estas que não são mencionadas por nenhum profissional participante da pesquisa.

Analisando os dois hospitais em questão, dos 20 profissionais entrevistados, 16 deles relataram ter vivenciado maior número de cesáreas do que parto normal, equivalente a $80 \%$. Esta análise é convergente com o que nos traz a literatura, ou seja, a incidência da taxa de realização de cesáreas prevalece superior em relação ao parto normal, ocupando atualmente $52 \%$ as taxas de cesariana no Brasil, chegando a $88 \%$ na rede privada, números muito superiores ao limite máximo de $15 \%$ proposto pela Organização Mundial da Saúde (OMS) (PERES et al., 2017). Segundo análise da pesquisa, o motivo pela realização do parto cesáreo é $50 \%$ por opção médica, seguido de $35 \%$ medo da dor do parto, ou seja, opção da mulher pela cesárea, tendo o mesmo percentual apontando para complicações médicas. Como traz a literatura, a alta prevalência de cesáreas no Brasil não está relacionada a mudanças no risco obstétrico e sim a fatores socioeconômicos e culturais, onde a preferência das mulheres pelo parto cesáreo é moldada pela conduta intervencionista do médico (COSTA et 
al., 2015). Já em relação ao parto normal, apesar de pouco realizado, quando ocorre é por opção de escolha da mulher, como aponta a pesquisa, onde mostra que $65 \%$ dos profissionais atribuem a realização do parto normal à escolha da mãe, seguido de outros critérios que aparecem como benefícios à saúde do bebê e recuperação mais rápida da mãe, tendo apenas o percentual de $25 \%$ dos profissionais que atribui a realização ao parto normal como escolha médica.

Em relação às práticas seguidas pelo hospital, práticas estas que se relacionam a condutas humanizadas ao parto, todos os profissionais relataram repassar informações as gestantes durante o período de pré-parto, parto e pósparto, porém o que de certa forma diverge com a questão da alta incidência de cesáreas justificáveis apenas pela escolha médica. Na decisão da escolha de via de parto, $95 \%$ dos profissionais relataram que a realização pela escolha é feita junto com a gestante. Porém, pelo que traz a literatura, a gestante é conduzida a sua decisão conforme é orientada durante as etapas que transcorre a gestação até a hora do parto (PINHEIRO et al., 2016). Todos os profissionais participantes da pesquisa dizem praticar acolhimento à família como também permitir a presença do acompanhante na hora do parto. Confirmando a literatura de que, a presença de acompanhante na hora do parto é um direito da mulher (LONGO; ANDRAUS; BARBOSA, 2010).

Tratando-se da questão do hospital propor educação continuada sobre o parto humanizado, a pesquisa aponta que $70 \%$ dos profissionais recebem educação continuada uma vez que $95 \%$ destes mesmos profissionais trazem que o hospital no qual exercem sua função preconiza o parto humanizado. Existe a necessidade de trazer o tema humanização no ensino profissional da área obstétrica, mais voltada para o compartilhamento de experiências, a fim de propiciar humanização em suas práticas (FERREIRA JÚNIOR; MAUCH; OSIS; BARROS, 2015). Como mostra a pesquisa e comparado em evidências que trazem a literatura, a enfermagem é a categoria responsável por trazer à equipe multiprofissional obstétrica a humanização, onde promoção de estratégias, como a "Rede Cegonha", inclui os enfermeiros no debate das questões à saúde da mulher, estimulando-os a desenvolver práticas norteadas pela humanização. Sendo perceptíveis dificuldades encontradas pela equipe de enfermagem na adoção de práticas de humanização em um centro obstétrico, sendo possível identificar que existem divergências nas relações interprofissionais de saúde atuantes nos mesmos cenários, dificultando assim a humanização no ambiente obstétrico (SILVA et al., 2018).

Entre as perguntas que compõem o questionário de pesquisa deste trabalho, existem duas questões descritivas em relação ao parto humanizado, uma é de que se o profissional tem conhecimento sobre o assunto, descrever então qual o conceito para o mesmo, e a segunda, quais as dificuldades encontradas para a realização do parto humanizado. Dentre os relatos dos profissionais, fica claro de que os mesmos tem conhecimento sobre o que é o parto humanizado, mas nenhum dos diferentes profissionais entrevistados 
relata que o parto humanizado é desfecho de um acompanhamento pré-parto de apoio e assistência, esclarecendo dúvidas e aliviando anseios, como também da importância do acompanhamento pós-parto. Sendo que existem gestantes que mesmo realizando todos os processos que contribuem ao desfecho de um parto natural, por complicações de saúde e que venham a por em risco a saúde da mãe e/ou do bebê acabam tendo como única alternativa a via de parto cesárea (PEREIRA et al., 2016). Sendo assim é possível exercer práticas as mais humanizadas possíveis dentro da realidade da parturiente. Colocação esta que em nenhum momento foi relatada pelos profissionais entrevistados, $\mathrm{o}$ que deixa evidente de que para os mesmos, o parto humanizado são práticas exercidas no momento da realização de um parto vaginal (normal).

Tais dados são evidenciados pelas falas a seguir.

Profissional médico: “O parto humanizado é para mim um parto com atenção e procedimentos que atendam a expectativa do paciente. Para a maior parte das pessoas, um parto sem intervenção".

Enfermeira: "Respeitar a gestante nas suas escolhas durante o trabalho de parto, oferecer um ambiente tranquilo com a presença do acompanhante de sal escolha, utilizar conhecimentos, práticas baseadas em evidências".

Técnica de enfermagem: "É a mulher ser dona do seu parto, optar pelo que é melhor no momento para ela e ter sempre acompanhante junto passando segurança".

Já em relação às principais dificuldades encontradas para por em prática o parto humanizado teve por unanimidade como resposta dos profissionais médicos de que o mesmo se da devido ao medo da gestante e familiares, falta de preparo da gestante, "tabus" de possíveis complicações no parto natural, dentre outros fatores relacionados a falta de condições psicológicas da gestante em conduzir um parto natural. Porém os relatos de profissionais enfermeiros e técnicos de enfermagem atribuem os obstáculos a realização do parto natural a resistência de alguns profissionais médicos, como também por parte da gestante e familiares, a insegurança, o medo da dor, do desconhecido, e do que esta por vir. Tais dados são evidenciados nas falas a seguir:

Médico: "Falta de orientação e conhecimento da paciente sobre o assunto, falta de preparo da paciente, judicialização da medicina".

Enfermeira: "Algumas práticas de alguns profissionais a "modo antigo"'".

Técnica de enfermagem: "O medo da dor".

Existe um contraponto em relação à gestante ser um dos principais entraves da realização do parto natural, uma vez que a literatura nos trás a influência do profissional que acompanha a gestante durante o pré-natal e as orientações recebidas nesse período é decisiva na escolha do tipo de parto (SANTANA; LAHM; SANTOS, 2015). Sendo apontados como determinantes 
no aumento da proporção de partos cesáreos no Brasil, questões não clínicas, como a idade e a escolaridade da mulher, a região de residência e os cuidados do pré-natal, além da influência do profissional que a assiste no pré-natal e no parto. Segundo pesquisas realizadas a preferência da gestante pela via de parto é a natural, porém nem sempre seu desejo é atendido (CABRAL et al., 2018). Portanto, conhecendo tal realidade torna-se evidente a necessidade de revisão e redirecionamento de práticas em relação ao parto, aproximando a educação continuada em relação a humanização do parto como rotina empregada ao ambiente hospitalar.

\section{CONCLUSÃO}

Os dados deste estudo mostram que as equipes dos dois hospitais apresentam bom conhecimento sobre os conceitos e diretrizes de um parto humanizado. Além disso, que os hospitais incentivam essa prática e, na sua maioria, oferecem programas de capacitação sobre o tema. Como sugestão, seria importante entrevistar gestantes e mães que frequentam ou frequentaram estes dois hospitais para verificar se o conhecimento demonstrado pelos profissionais é colocado em prática no dia-a-dia de atendimento.

\section{REFERÊNCIAS}

BRASIL, Ministério da Saúde. Programa Humanização do parto Humanização no Pré-Natal e Nascimento. Brasília: Ministério da Saúde, 2002. Disponível em: http:/ / bvsms.saude.gov.br/bvs/publicacoes/parto.pdf. Acesso em: 01 jul. 2019.

BRASIL, Ministério da Saúde. Secretaria de Políticos de Saúde. Área Técnica de Saúde da Mulher. Parto, aborto e puerpério: assistência humanizada à mulher. Brasília: Ministério da Saúde, 2001. Disponível em: http://bvsms.saude.gov.br/bvs/ publicacoes/cd04_13.pdf. Acesso em: 01 jul. 2019.

BUSANELLO, Josefine et al. Humanização do parto e a formação dos profissionais da saúde. Ciência, Cuidado e Saúde, Maringá, v. 10, n. 1, p. 169-175, jan./mar. 2011. Disponível em: http://periodicos.uem.br/ojs/index.php/CiencCuidSaude/article/ view/8533/pdf. Acesso em: 01 jul. 2019.

CABRAL, Symara Abrantes Albuquerque de Oliveira et al. Conhecimento das Gestantes acerca do Parto na Admissão. Id on Line Rev. Mult. Psic. V, v. 12, n. 39, p. 851-864, 2018. Disponível em: https://idonline.emnuvens.com.br/id/article/ view/1034/1486. Acesso em: 01 julho de 2019.

COSTA, Maiara Neves et al. Parto: direito de escolha da mulher. Saber Digital, Valença, v.8, n.1, p. 146-163, 2015. Disponível em: http:/ / revistas.faa.edu.br/index. php/SaberDigital/article/view/395/302. Acesso em: 01 jul. 2019.

FERREIRA JÚNIOR, Antônio Rodrigues; MAKUCH, Maria Yolanda; OSIS, Maria José Martins Duarte; BARROS, Nelson Filice de. Percepções de profissionais de 
enfermagem sobre a humanização em obstetrícia. SANARE, Sobral, v.14, n.2, p. 2735, jul./dez. 2015. Disponível em: https://sanare.emnuvens.com.br/sanare/article/ view/821/492. Acesso em: 01 jul. 2019.

GRIBOSKI, Rejane Antonello; GUILHEM, Dirce. Mulheres e profissionais de saúde: o imaginário cultural na humanização ao parto e nascimento. Texto e Contexto Enfermagem, Florianópolis, v. 15, n. 1, p. 107-114, mar. 2006. Disponível em: http:/ / www.scielo.br/pdf/tce/v15n1/a13v15n1.pdf. Acesso em: 01 jul. 2019.

LONGO, Cristiane Silva Mendonça; ANDRAUS, Lourdes Maria Silva; BARBOSA, Maria Alves. Participação do acompanhante na humanização do parto e sua relação com a equipe de saúde. Revista Eletrônica de Enfermagem, v. 12, n. 2, p. 386-391, abr./jun. 2010. Disponível em: https: / /www.fen.ufg.br/fen_revista/v12/n2/ v12n2a25.htm. Acesso em: 01 jul. 2019.

MALHEIROS, Paolla Amorim et al. Parto e nascimento: Saberes e práticas humanizadas. Texto e Contexto - Enfermagem, Florianópolis, v. 21, n. 2, p. 329-337, abr./jun. 2012. Disponível em: http:/ / www.scielo.br/pdf/tce/v21n2/a10v21n2. Acesso em: 01 jul. 2019.

MATEI, Elizabete Martins et al. Parto humanizado: um direito a ser respeitado. Cadernos, São Paulo, v. 9, n. 2, p. 16-26, abr./jun. 2003. Disponível em: http:/ /bvsms. saude.gov.br/bvs/is_digital/is_0403/pdf/IS23(4)104.pdf. Acesso em: 01 jul. 2019.

MENEZES, Maria Brito Gonçalves; DIAS, Daniela Fernandes Soares. A humanização do cuidado no pré-parto e parto. SynThesis Revista Digital FAPAM, Pará de Minas, n.3, p. 24-36, abr. 2012. Disponível em: http:/ / fapam.web797.kinghost.net/revista/ volume3/4\%20Marisa\%20Daniella\%20-\%2024\%20A\%2036.pdf. Acesso em: 01 jul. 2019.

NOGUEIRA, Elizandra Medianeira Razera. Criação de um protocolo de humanização do nascimento por meio do parto cesárea em um hospital de médio porte da cidade de Santa Maria - RS. Dissertação (pós-Graduação em Saúde Materno Infantil), Centro Universitário Franciscano, Santa Maria, 2017. Disponível em: http:/ /www.tede. universidadefranciscana.edu.br:8080/bitstream/UFN-BDTD/645/5/Dissertacao_ ElisandraMedianeiraRazeraNogueira.pdf. Acesso em: 01 jul. 2019.

PEREIRA, Sinara Santos et al. Parto Natural: a atuação do enfermeiro diante da assistência humanizada. Tempus, acta de saúde coletiva, Brasília, v.10, n.3, p. 199-213, set. 2016. Disponível em: http:/ / www.tempus.unb.br/index.php/tempus/article/ view/1727/1682. Acesso em: 01 jul. 2019.

PERES, Roberta Silvestre Fontão et al. Análise Qualitativa do Parto Humanizado do Distrito Federal por Diferentes Grupos Profissionais dos Serviços Públicos e Privados de Saúde. XVII Safety, Health and Environment World Congress, Vila Real, p. 104-104, jun. 2017.Disponível em: http:/ / copec.eu/shewc2017/proc/works/25.pdf. Acesso em: 01 jul. 2019. 
PINHEIRO, Bruna Cardoso; BITTAR, Cléria Maria Lobo. Percepções, expectativas e conhecimentos sobre o parto normal: relatos de experiência de parturientes e dos profissionais de saúde. Aletheia, Canoas, n. 37, p. 212-227, abr. 2012. Disponível em: http:/ / pepsic.bvsalud.org/scielo.php?script=sci_ arttext\&pid=S1413-03942012000100015. Acesso em: 01 jul. 2019.

PINHEIRO, Thainá Meirelles et al. Fatores que influenciam na indicação da via de parto. Revista de Enfermagem do Centro Oeste Mineiro, v.1, n.6, p. 2066-2080, 2016. Disponível em: http:/ / www.seer.ufsj.edu.br/index.php/recom/article/ view/986/1013. Acesso em: 01 jul. 2019.

SANTANA, Fernanda Alves; LAHM, Janaína Verônica; SANTOS, Reginaldo Passoni dos. Inserção de enfermeiras obstétricas no atendimento ao parto: percepção da equipe de Enfermagem. Revista da Faculdade de Ciências Médicas de Sorocaba, Sorocaba, v.17, n.3, p. 123-127, 2015.

SCHMALFUSS, Joice Moreira et al. O cuidado à mulher com comportamento não esperado pelos profissionais no processo de parturição. Ciências, cuidado e Saúde, Maringá, vol. 9, n. 3, p. 618-623, jul./set. 2010. Disponível em: http:/ / periodicos.uem. br/ojs/index.php/CiencCuidSaude/article/view/9533/6658. Acesso em: 01 jul. 2019.

SILVA, Renata Martins da et al. Inserção de enfermeiras obstétricas no atendimento ao parto: percepção da equipe de Enfermagem. RIES, Caçador, v.7, n.1, p. 293-302, 2018. Disponível em: http:/ / periodicos.uniarp.edu.br/ries/article/view/1240/813. Acesso em: 01 jul. 2019. 